\title{
Characterization and Catalytic Activity of Different Carbon Supported Pd Nanocomposites
}

\author{
László Vanyorek $^{1} \cdot$ Gyula Halasi $^{2} \cdot$ Péter Pekker $^{3} \cdot$ Ferenc Kristály $^{4} \cdot$ Zoltán Kónya $^{2}$
}

Received: 3 June 2016 / Accepted: 1 September 2016

(C) European Union 2016

\begin{abstract}
In our experiments, high nitrogen content $\mathrm{N}$-doped multiwall carbon nanotubes (N-CNTs) were synthetized by chemical vapour deposition (CVD) method, after these nanotubes were used as dehydrogenation catalyst support. The chemical nature of the nitrogen atoms in graphitic lattice of $\mathrm{N}$ doped CNT was characterized with X-ray photoelectron spectroscopy (XPS) analysis, the pyridinic and graphitic nitrogen atoms were located in nanotube wall. The lattice defects of N-CNT structure were checked with Raman spectroscopy, according to which many defect were present in structure of N-CNTs, owing to the incorporated nitrogen atoms. The formed oxidized N-doped CNT samples were studied by Fourier transform infrared (FTIR) spectroscopy, according to the test, many oxygen content surface functional groups were identified $(\mathrm{COOH}, \mathrm{OH}$ and $\mathrm{C}=\mathrm{O}$ ). Palladium nanoparticle morphology and surface on the catalyst substrates were characterized by high
\end{abstract}

Electronic supplementary material The online version of this article (doi:10.1007/s10562-016-1857-8) contains supplementary material, which is available to authorized users.

László Vanyorek

kemvanyi@uni-miskolc.hu

1 Institute of Chemistry, University of Miskolc, Miskolc-Egyetemváros 3515, Hungary

2 Department of Applied and Environmental Chemistry, University of Szeged, Rerrich Béla tér 1. Szeged 6720, Hungary

3 MTA-ME Materials Science Research Group, Miskolc-Egyetemváros 3515, Hungary

4 Institute of Mineralogy and Geology, University of Miskolc, Miskolc-Egyetemváros 3515, Hungary resolution transmission electron microscopy (HRTEM) and $\mathrm{X}$-Ray diffraction (XRD) methods. The diameters of palladium particles were slightest in case of carbon nanotube supported catalyst $(2 \mathrm{~nm})$, smaller than case of activated carbon, due to absence of microporosity and presence of functional groups on the N-CNT surface. The catalytic activity of the CNT supported catalysts was compared to an active carbon and norit supported samples. The dehydrogenation of $\mathrm{C}_{2} \mathrm{H}_{6}$ has been investigated on Pd deposited on various carbon supported catalysts at 573-973 K. On the $\mathrm{Pd} / \mathrm{CNT}$ catalyst the highest selectivity was reached to ethene $(85 \%)$ at $973 \mathrm{~K}$. The most active $\mathrm{Pd} / \mathrm{Ac}$ achieved $64 \%$ conversion at $973 \mathrm{~K}$.

\section{Graphical Abstract}
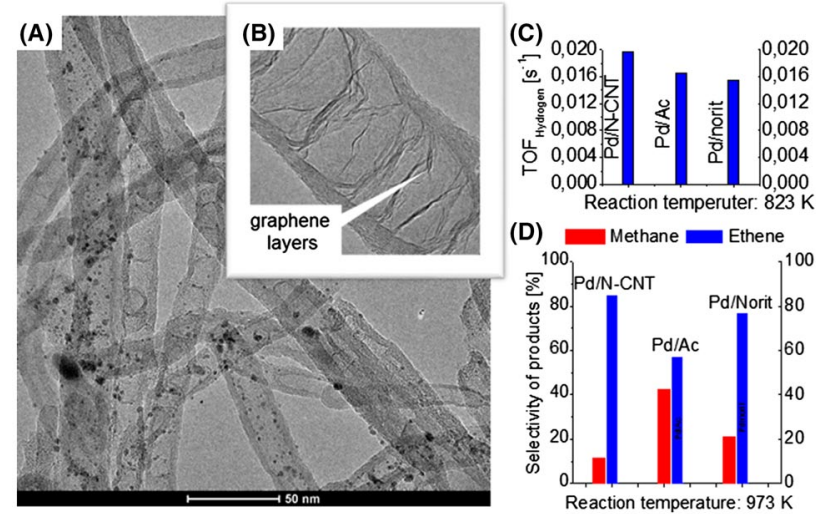

Keywords N-doped CNT - CVD method · Raman and infrared spectra $\cdot$ Pd deposited on carbon . Decomposition of ethane 


\section{Introduction}

Belonging to the group of carbon nanomaterials, the carbon CNTs are useful materials as heterogeneous catalyst supports owing to their high specific surface area, good mechanical attribution and thermal stability. These nanomaterials were successfully used in heterogeneous catalytic reactions including hydro-desulfurization [1], hydro-formylation [2], Fischer-Tropsch [3], oxidation process [4] and hydrogenation reactions [5]. When the performance of catalysts supported on nanotubes and other carbon allotropes was compared in e.g. the dehydrogenation of ethyl-benzene and the hydrogenation of nitro-cyclohexane and methyl-styrene, higher catalytic activity and selectivity was observed over CNT-supported catalysts [6-8]. In case of carbon nanotubes no located micropores in their structure compared to the activated carbon forms. The absence of microporosity lead to the high reaction rate during catalytic reactions, this phenomenon can be attributed the active phase on the surface of CNT easy access to the molecules, thereby mass-transfer limitation can be overcome [7, 8]. Controlling the morphology of nanocarbons has been shown to be effective in fine-tuning the performance of catalysts. Their special interaction with deposited metals makes carbon nanotubes good heterogeneous catalytic support materials [9-11] There is a wide variety of carbon nanotube (CNT) synthesis methods, but the most widespread method of all is the catalytic vapor deposition (CVD), where gaseous hydrocarbons are thermally decomposed in the presence of catalytically active metals [12, 13].

Choosing the synthesis parameters can significantly alter the number of lattice defects appearing within the structure of the nanotubes can be modified [14]. The lattice defects can be attributed to the vacancies and pentagon-heptagon pairs built into the walls of nanotubes [15]. By carefully selecting the carbon source, it becomes possible to form an active structure that contains high energy lattice-defects, which can be well utilized in heterogeneous catalysis. Raman spectroscopy is a well suitable technique for the characterization of nanotubes [16] since the ratios of the so called G (graphite) and D (defect) bands are based upon the frequency of the lattice defects [17]. The lattice defects found within the lateral area of the nanotubes also play an important role in establishing functional groups onto the surface of nanotubes [18]. The hydrophilic character of nanotubes may be improved by attaching functional groups to the surface of tubes, which results in a higher degree of dispersibility [12].

The nitrogen content leads to numerous defects sites on the nitrogen doped carbon nanotube, which provides anchoring sites towards reactant molecules and catalytically active metal ions or complexes. The nitrogen doped carbon nanotubes are thermally less stable compared to their non-doped counterparts, thereby the doped nanotubes were easily oxidized by chemical or physical methods. The oxidized nanotubes were more dispersible in aqueous media than the non-oxidized forms. The high dispersion stability is important to the catalyst production, because it leads to the high dispersion of metal nanoparticles. The catalyst with high dispersion shows enhanced catalytic activity. The conversion of alkanes into more valuable compounds is an important purpose for heterogeneous catalysis [19, 20]. There is a great variety in the reactivity of alkanes. Whereas both the decomposition and dry reforming of methane requires high temperature even on the most active $\mathrm{Rh}[21$, 22], the reactions of $\mathrm{C}_{2} \mathrm{H}_{6}[23,24]$ and $\mathrm{C}_{3} \mathrm{H}_{8}$ [25] proceeds at significantly lower temperatures. In the present work the influence of support on the reaction of $\mathrm{C}_{2} \mathrm{H}_{6}$ is investigated over $\mathrm{Pd}$ nanoparticles deposited on various carbonic supports. An alternative way of the conversion of $\mathrm{C}_{2} \mathrm{H}_{6}$ is its dehydrogenation to $\mathrm{C}_{2} \mathrm{H}_{4}$, which is one of the most important petrochemicals. On the most active catalysts, however, the decomposition of $\mathrm{C}_{\mathrm{x}} \mathrm{H}_{\mathrm{y}}$, formed during the reaction cannot be avoided.

\section{Materials and Methods}

\subsection{Materials}

The nitrogen doped carbon nanotubes were prepared with catalytic vapour deposition method during which hydrocarbons in vapour phase are decomposed in the presence of catalytically active metals. We have used cyclohexylamine (Charlau Chem.) for synthesis of the N-doped CNTs (N-CNT). Nickel nitrate hexahydrate $\mathrm{Ni}\left(\mathrm{NO}_{3}\right)_{2} \cdot 6 \mathrm{H}_{2} \mathrm{O}$ (Merck Chem) and magnesium-oxide $\mathrm{MgO}$ (Reanal) have been used as precursors for the preparation of $\mathrm{Ni} / \mathrm{MgO}$ catalyst. Surface modification of the nanotubes was carried out using oxidative treatment where the CNT samples were treated with $65 \mathrm{wt} \%$ nitric acid (Sigma Aldrich) and $98 \mathrm{wt} \%$ sulfuric acid (Merck Chem.). The different carbon supports (N-CNTs, activated carbon and norit CA1 Sigma Aldrich) were impregnated by aqueous solution of palladium chloride (Chinoin) to form $\mathrm{Pt}$ nanoparticles containing catalysts. Ethane was the product of Messer with purity of 3.5.

\subsection{Synthesis of N-doped Carbon Nanotubes}

The CVD synthesis was carried out by applying nitrogen atmosphere in a quartz-reactor, which was placed in a tube furnace (Fig. 1). The chosen carbon source was evaporated in a pre-furnace. The amine-containing carbon precursor, cyclohexylamine was precisely fed by using a syringe pump, which injected the carbon-source directly into the main furnace, where it was immediately evaporated and 
Fig. 1 Experimental layout applied for the manufacturing of nanotubes (1) $\mathrm{N}_{2}$ feed; (2) $\mathrm{N}_{2}$ flowmeter; (3) pump to feed hydrocarbons; (4) organic precursor evaporator furnace; (5) $\mathrm{CH}_{\mathrm{x}}$ tube-furnace, heating control unit; (6) quartz reactor; (7) pyrolysis furnace; (8) quartz-bowl with the catalyst

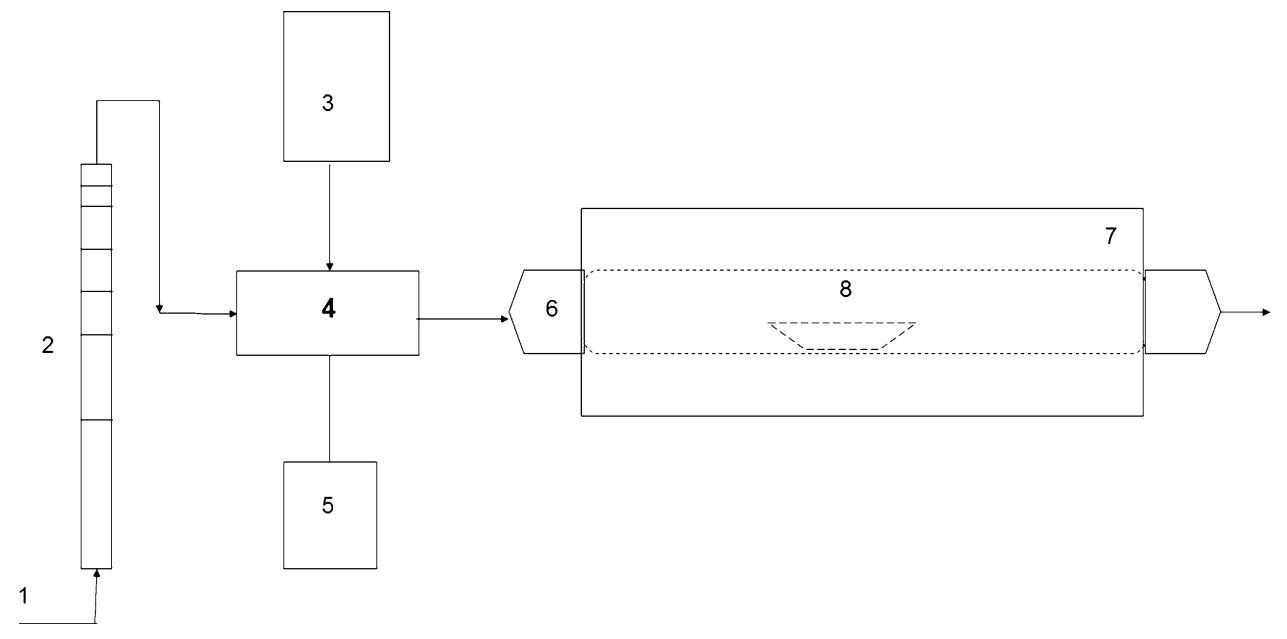

\subsection{Characterization}

Morphology tests of N-CNT samples were carried out with transmission electron microscopy (Philips CM 10, $100 \mathrm{kV}$ ) and a FEI TECNAI G ${ }^{2} 20$ X-Twin high-resolution transmission electron microscope (equipped with electron diffraction) operating at an accelerating voltage of $200 \mathrm{kV}$. All samples were dribbled onto 300 Mesh copper grids (Ted Pella Inc.) from an aqueous suspension. The products were examined by TEM, while the outer diameters of these nanotubes were manually scaled using the ImageJ.

Purity of N-CNTs were checked with thermogravimetric test (TG) applying a MOM Derivatograph-C device in oxidative atmosphere, the heating rate was $5 \mathrm{~K} / \mathrm{min}$.

The chemical nature of the nitrogen in the graphitic lattice of N-CNTs were characterized with X-ray photoelectron spectroscopy (SPECS spectroscope with Phoibos 150 MCD nine analyzer).

The lattice defects of N-CNT structure were checked with Raman spectroscopy. WITEC Confocal Raman microscope alpha $300 \mathrm{R}$ equipped with a He-Ne laser emitting at $\lambda=632.95 \mathrm{~nm}$ has been applied for these experiments. The $\mathrm{N}$ content was determined by Vario Macro CHNS element analyzer and it was $2.8 \mathrm{wt} \%$.

The presence of the functional groups on the surface was identified using FTIR. The surface-treated nanotubes were examined using a Vertex 70 type Fourier transform infrared spectroscope. In the course of the sample preparation the $\mathrm{N}$-CNT samples were embedded into $\mathrm{KBr}$ pastilles $(0.4 \mathrm{mg}$ $\mathrm{BCNT}$ in $250 \mathrm{mg} \mathrm{KBr}$ ). Palladium nanoparticle morphology was examined by HRTEM (FEI Technai G2, 200 kV). XRD measurement were carried out with a Bruker D8 Advance diffractometer.

The surface area of the carbon support was determined by a Micromeritics ASAP 2020 instrument. Assuming the metal particles to be spherical [26] particle sizes d (m) can be calculated from the dispersion values $\mathrm{D},(\% / 100)$ using the following equation: 
$D=\frac{6 \mathrm{~A}}{\rho \delta \mathrm{Ld}}$

where $\mathrm{A}=$ atomic mass $106.42 \mathrm{gmol}^{-1}, \rho=$ density $12.02 \times 10^{6} \mathrm{gm}^{-3}, \delta=$ average surface area occupied by one Pd atom $0.79 \times 10^{-19} \mathrm{~m}^{2}$, and $\mathrm{L}=$ Avogadro's constant [26]. Data are listed in Table 1 .

\subsection{Catalytic Studies}

Catalytic measurements were carried out at $1 \mathrm{~atm}$ pressure in a fixed bed continuous flow reactor made of a quartz tube (i.d. $8 \mathrm{~mm}$ ). The flow rate of reactant gases was $12 \mathrm{ml} / \mathrm{min}$. The carrier gas was $\mathrm{Ar}$, which was mixed with $\mathrm{C}_{2} \mathrm{H}_{6}$ at room temperature. The carrier gas contained $12.5 \%$ of $\mathrm{C}_{2} \mathrm{H}_{6}$. The weight of the catalysts was $\sim 200 \mathrm{mg}$. The exit gas was analysed by gas chromatograph (Hewlett-Packard 5890) on a Porapak QS column. The conversion of ethane was calculated from the amount of $\mathrm{C}_{2} \mathrm{H}_{6}$ consumed. However, it was also determined on the basis of the $\mathrm{H}$ and $\mathrm{C}$ contents of the reactant and products. The catalysts were reduced at $673 \mathrm{~K}$ for $1 \mathrm{~h}$ in situ before the experiments in all cases. Hydrogen and different product selectivities were defined as:
$S_{H_{2}}=\frac{x_{H_{2}}}{\sum x_{i} n_{i}}, \quad S_{i}=\frac{x_{i} n_{i}}{\sum x_{i} n_{i}}$

where $\mathrm{x}_{\mathrm{i}}$ and $x_{\mathrm{H}_{2}}$ are the mole fractions of product (i) and $\mathrm{H}_{2}$, respectively, and $\mathrm{n}_{\mathrm{i}}$ is half of the number of hydrogen atoms (in the calculation of $S_{H_{2}}$ ) or number of carbon atoms (in the calculation of $\mathrm{S}_{\mathrm{i}}$ ) in each molecule of product (i).

\section{Results and Discussion}

\subsection{Characterization of the Carbon Nanotubes Morphology and Purity with Transmission Electron Microscopy and Thermogravimetric Analysis}

The structure of the N-doped nanotubes can be seen on the TEM picture showing the bamboo like walls of the tubes (Fig. 2a). There are significant difference in structure of bamboo like nitrogen doped carbon nanotubes, counter to the non-doped counterparts, namely a periodical bambooshaped structure of BCNT. In case of bamboo like carbon nanotubes the microstructure of the tips is enclosed by complete graphitic fringes. Formation of aforementioned

Table 1 Some characteristic data for the catalysts and catalytic reaction on Pd promoted carbon supports

\begin{tabular}{|c|c|c|c|c|c|c|}
\hline Samples & $\begin{array}{l}\text { Dispersion of the } \\
\text { metals (\%) }\end{array}$ & $\begin{array}{l}\text { Average size of Pd } \\
\text { particles }(\mathrm{nm})\end{array}$ & $\begin{array}{l}\text { BET surface area } \\
\text { of the support }\left(\mathrm{m}^{2}\right)\end{array}$ & $\begin{array}{l}\text { Conversion of } \\
\mathrm{C}_{2} \mathrm{H}_{6} \text { at } 823 \mathrm{~K}\end{array}$ & $\begin{array}{l}\text { Turnover frequency at } \\
823 \mathrm{~K}\left(\mathrm{TOF}_{\mathrm{H}_{2}}\right)(1 / \mathrm{s})\end{array}$ & $\begin{array}{l}\mathrm{S} \% \\
\text { values of } \\
\mathrm{CH}_{4} / \mathrm{C}_{2} \mathrm{H}_{4} \\
\text { at } 823 \mathrm{~K}\end{array}$ \\
\hline $\mathrm{Pd} / \mathrm{CNT}$ & 82.8 & 3.1 & 146 & 17.9 & 0.0198 & $51 / 45$ \\
\hline $\mathrm{Pd} /$ norit & 35.3 & 4.7 & 859 & 7.21 & 0.0155 & $5.5 / 93.5$ \\
\hline $\mathrm{Pd} / \mathrm{Ac}$ & 53.4 & 2.0 & 328 & 11.89 & 0.0166 & $13 / 87$ \\
\hline
\end{tabular}

$\mathrm{TOF}_{\mathrm{H}_{2}}$ : the amount of $\mathrm{H}_{2}$ formed related to the number of metal atoms
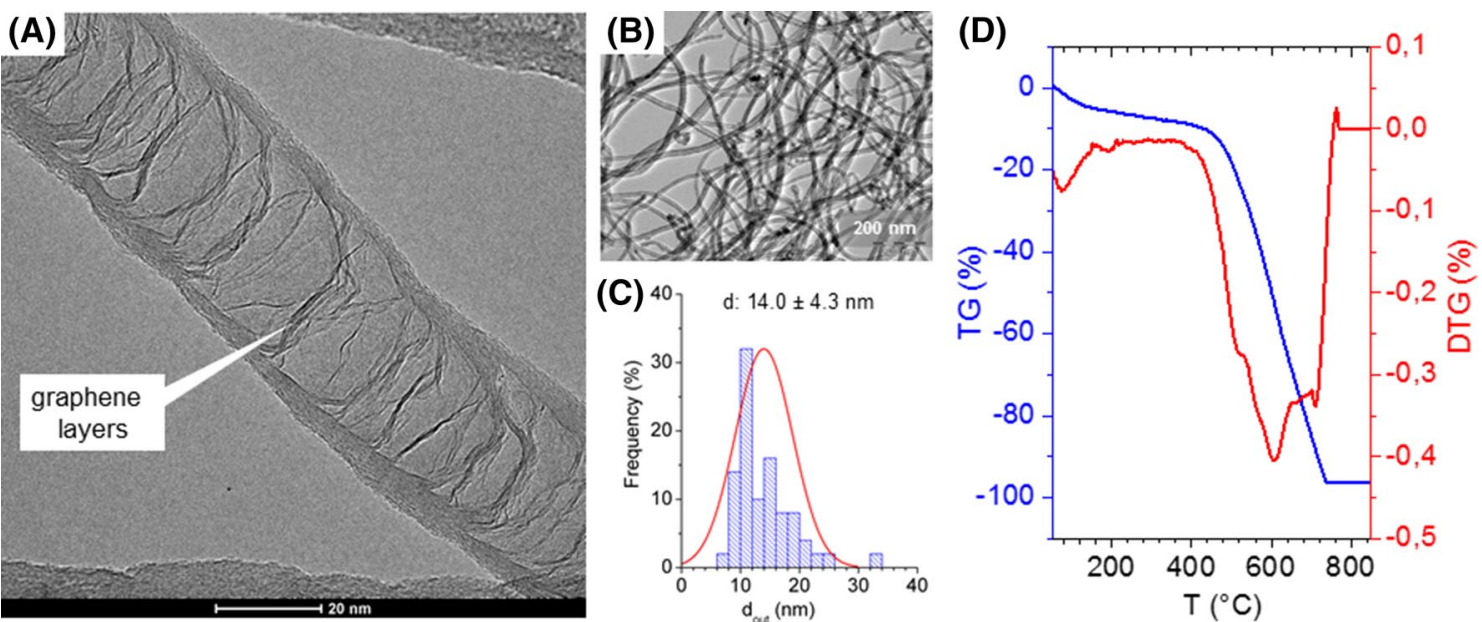

Fig. 2 HRTEM picture of graphene layers in the structure of N-CNT (a), TEM image of N-CNT and size distribution of tube diameter (b, c) and thermogravimetric curves of the bamboo-shaped carbon nanotubes (d) 
structures owing to the incorporation of nitrogen atoms in the graphitic wall. The products were examined by TEM, while the outer diameter of nanotubes was manually scaled using the ImageJ program (Fig. 2b). The distribution of nanotube diameters is plotted on Fig. $2 \mathrm{c}$ as well. The average outer diameter of nanotubes is $14 \mathrm{~nm}$. On the TEM picture amorphous carbon or catalyst residue was not observed.

The purity of the CNT product was checked with thermogravimetric analysis. The DTG curve shows that N-CNT sample started to burn/oxidize at $\sim 690 \mathrm{~K}$ (Fig. 2d). This low ignition temperature of N-CNT can be explained as a consequence of the CVD synthesis, i.e. the residual catalyst metal particles $(\mathrm{Ni})$ and metal oxides could promote the oxidation of carbon nanotubes, causing a decrease of the ignition temperature. Furthermore, the defects on the wall (curved surface) of nanotubes could also contribute to the lowering the ignition temperatures. The measured carbon content of the sample was $96.5 \mathrm{wt} \%$.

\subsection{Results of XPS, Raman and FTIR Analysis}

The XPS is a very good technique to study the chemical nature of the incorporated nitrogen in the structure of $\mathrm{N}$ doped carbon nanotubes. The peaks in the XPS spectra assigned the pyridine-like nitrogen with $398.3-399.8 \mathrm{eV}$ binding energy. The band in the $401.0-401.4 \mathrm{eV}$ binding energy interval is due to the incorporation of quaternary nitrogen into the nanotube structure. The peak of the nitrogen oxide species and/or intercalated nitrogen molecules can be assigned in binding energy range of $404.0-405.6 \mathrm{eV}$. The deconvoluted N1s spectra of N-doped CNT sample assignment of different types of nitrogen defects, at $398.6 \mathrm{eV}$ binding energy indicated the pyridine-like $\mathrm{N}$ atoms. The peak at $401.2 \mathrm{eV}$ can be assigned to quaternary type nitrogen (Fig. 3a). The binding energy at $404.9 \mathrm{eV}$ supporting the presence of adsorbed nitrogen or nitrogen oxides in the CNT lattice. The peak maximum at $410.5 \mathrm{eV}$ is the shake up satellite.
Fig. 3 XP spectra of N doped CNT (N1s) (a), Raman spectra of the functionalized nanotubes (b), FT-IR spectra of oxidized CNTs (c)
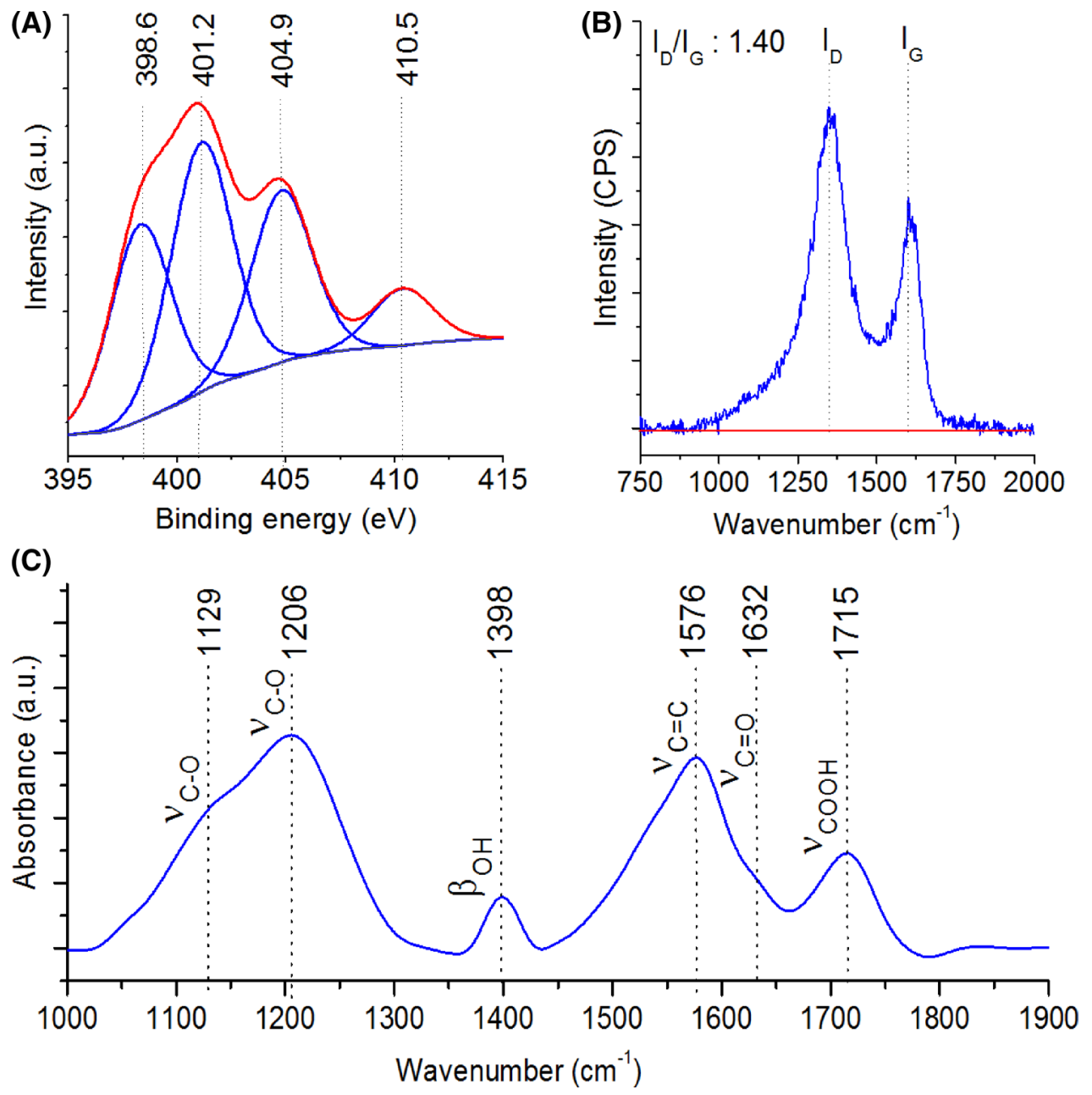
Raman spectroscopy studies of N-CNT samples have been performed to determine the frequency of defects appeared in the structure (Fig. 3b). Bands found at $1390 \mathrm{~cm}^{-1}$ are characteristic for the so-called 'defect vibration' (D) while bands at $1590 \mathrm{~cm}^{-1}$ can be attributed to the graphitic structure $(\mathrm{G})$. The structural integrity of the carbon nanotubes can be characterized by direct comparison of the $\mathrm{I}_{\mathrm{D}} / \mathrm{I}_{\mathrm{G}}$ intensity ratios of the mentioned vibrations [16]. The structural defects of nanotubes play an important role in their catalytic activity. Their chemical reactivity is also affected by defects. The N-CNT samples shows relatively great $\mathrm{I}_{\mathrm{D}} / \mathrm{I}_{\mathrm{G}}$ ratio (1.4), compared to the non-doped counterparts (SWCNT, MWCNT). $\mathrm{I}_{\mathrm{D}} / \mathrm{I}_{\mathrm{G}}$ ration of nitrogen free, multiwall carbon nanotubes from acetylene were 1.05, [27] In the case of highly oriented pyrolytic graphite, the $\mathrm{D}$ band not visible on the Raman spectra, the $\mathrm{I}_{\mathrm{D}} / \mathrm{I}_{\mathrm{G}}$ of the high graphitized single wall carbon nanotube was obtained 0.09 [28, 29].

The FT-IR results of the oxidized N-CNT sample is shown on Fig. 3c. The stretching vibrations typical for -OH groups appeared in the $2800-3620 \mathrm{~cm}^{-1}$ (not shown) and $1390-1410 \mathrm{~cm}^{-1}$ ranges. The bands characterizing the $\mathrm{C}-\mathrm{O}$ and $\mathrm{C}-\mathrm{O}(\mathrm{H})$ bonds of the hydroxyl group $v_{\mathrm{C}-\mathrm{O}(\mathrm{H})}$ vibration mode appeared at around $1100-1170 \mathrm{~cm}^{-1}$ wavenumbers, and the stretching vibration band of phenolic $\mathrm{OH}$ group at around $1140-1230 \mathrm{~cm}^{-1}$, respectively. Stretching vibrations in the range of $1700-1730 \mathrm{~cm}^{-1}$ were a feature of the carboxyl group. The functionalization of nanotube surfaces was followed by examining some well separable functional groups: the vibration bands of the $-\mathrm{C}-\mathrm{O}$ bond at 1129 and $1206 \mathrm{~cm}^{-1}$; that of the $-\mathrm{OH}$ group at $1398 \mathrm{~cm}^{-1}$ and of the $-\mathrm{COOH}$ band at $1715 \mathrm{~cm}^{-1}$. The peak observed at $\sim 1632 \mathrm{~cm}^{-1}$ can be assigned as the vibration of $\mathrm{C}=\mathrm{O}$ groups. A spectral feature observed at $\sim 1206 \mathrm{~cm}^{-1}$ can be attributed to the stretching vibration of $\mathrm{C}-\mathrm{O}$ in phenols [30]. The peak at $\sim 3430 \mathrm{~cm}^{-1}$ can be assigned to $-\mathrm{OH}$ stretching vibration $[18,19]$. The $\mathrm{C}=\mathrm{C}$ vibration bands at $1576 \mathrm{~cm}^{-1}$ represent the vibration of the lattice structure of the carbon nanotube.

\subsection{Characterization of Palladium Containing Catalysts}

Palladium-promoted N-CNT sample and the Pd decorated activated carbon supported catalyst were studied with HRTEM and XRD techniques. The detailed characterization of supported Pd catalysts can be seen on Fig. 4. Palladium nanoparticle morphology was examined by HRTEM (Fig. 4a, d, g). The HRTEM image analysis revealed that the average size of the palladium particles on the carbon nanotube surface was smaller than on the activated carbon surface and in case of norit supported catalyst. The average Pd nanoparticle diameter on the nanotube substrate was $2.0 \mathrm{~nm}$, on the activated carbon supported catalyst was
$3.1 \mathrm{~nm}$ and the norit support was $4.7 \mathrm{~nm}$ (Fig. 4c, f, i). This phenomenon can be explained with the presence of defect sites (pentagons and heptagons) in the wall of N-CNT. These heptagon and pentagon sites induced by the nitrogen doping results in localized electronic charges, which lead to formation of electronic interactions between palladium nanoparticles and defect sites and can be attributed to the smaller particle size of Pd. The nickel what was found in carbon nanotubes support is originated from the catalyst used in CCVD nanotube synthesis.

The X-ray diffractometric measurements confirmed the presence of the elemental palladium in catalysts. The XRD results were showed on the Fig. $4 \mathrm{~b}, \mathrm{e}, \mathrm{h}$. The peak at 26.5 $\Theta^{\circ}$, was indexed as the $C(002)$ reflection of the hexagonal graphite in N-CNT (Fig. 4h). The peaks at $40.12 \Theta^{\circ}$; $46.72 \Theta^{\circ} ; 68.12 \Theta^{\circ}$ and $82.12 \Theta^{\circ}$ degrees present in $\mathrm{Pd} / \mathrm{Ac}$, $\mathrm{Pd} / \mathrm{N}-\mathrm{CNT}$ and $\mathrm{Pd} /$ Norit catalysts were indexed as the Pd (111), Pd (200), Pd (220) and Pd (311) reflections of palladium nanoparticles (JCPDS 46-1043). The peak at $43.22 \Theta^{\circ}$ is assigned to the $\mathrm{Ni}$ (111) reflection (the remained nickel owing to the CVD synthesis of BCNT).

The palladium content of catalysts were measured by ICP-OES, which was $5.2 \mathrm{wt} \%$ in the activated carbon supported sample, in case of norit-palladium was $5.0 \mathrm{wt} \%$ and on the surface of N-CNT was $4.8 \mathrm{wt} \%$.

\subsection{Catalytic Activity of Supported Pd Catalyst in Ethane Decomposition}

Experiments were executed in the temperature range of $523-973 \mathrm{~K}$. The reaction of $\mathrm{C}_{2} \mathrm{H}_{6}$ started on most of the catalysts at high temperature, above 650-700 K (Fig. 5). The conversion was $3-8 \%$ at $773 \mathrm{~K}$ and the largest value was obtained over $973 \mathrm{~K}(64 \%)$ on $\mathrm{Pd} / \mathrm{Ac}$. The highest activity was showed by $\mathrm{Pd} / \mathrm{Ac}$, followed by $\mathrm{Pd} / \mathrm{N}-\mathrm{CNT}$, $\mathrm{Pd} /$ norit. The major product was $\mathrm{C}_{2} \mathrm{H}_{4}$. High selectivity, $>80 \%$, was measured for N-CNT sample (Fig. 5 b), which altered with the temperature. However significant amount of $\mathrm{CH}_{4}$ was formed as well, especially on high temperatures on the norit support the methane became the major product. All the catalysts exhibited a remarkable stability except for the activated carbon where the conversion start to decrease dramatically after $300 \mathrm{~min}$. Calculation of the conversion on the consumption of ethane showed a good agreement with the values based on the $\mathrm{H}$ content of the product. The methane/ethene ratio was presented on Fig. $5 \mathrm{~b}$ which was the lowest on $\mathrm{Pd} / \mathrm{N}-\mathrm{CNT}$ and the highest on the active carbon supported catalyst. Despite the large amount of ethene formation aromatic products was detected in only traces. The TOF values were determined on $823 \mathrm{~K}$ to avoid the high conversion values; the most active catalyst was the $\mathrm{Pd} / \mathrm{N}-\mathrm{CNT}$, with a tiny difference from the Pd/Ac. We should notice that the activated carbon supported sample on 

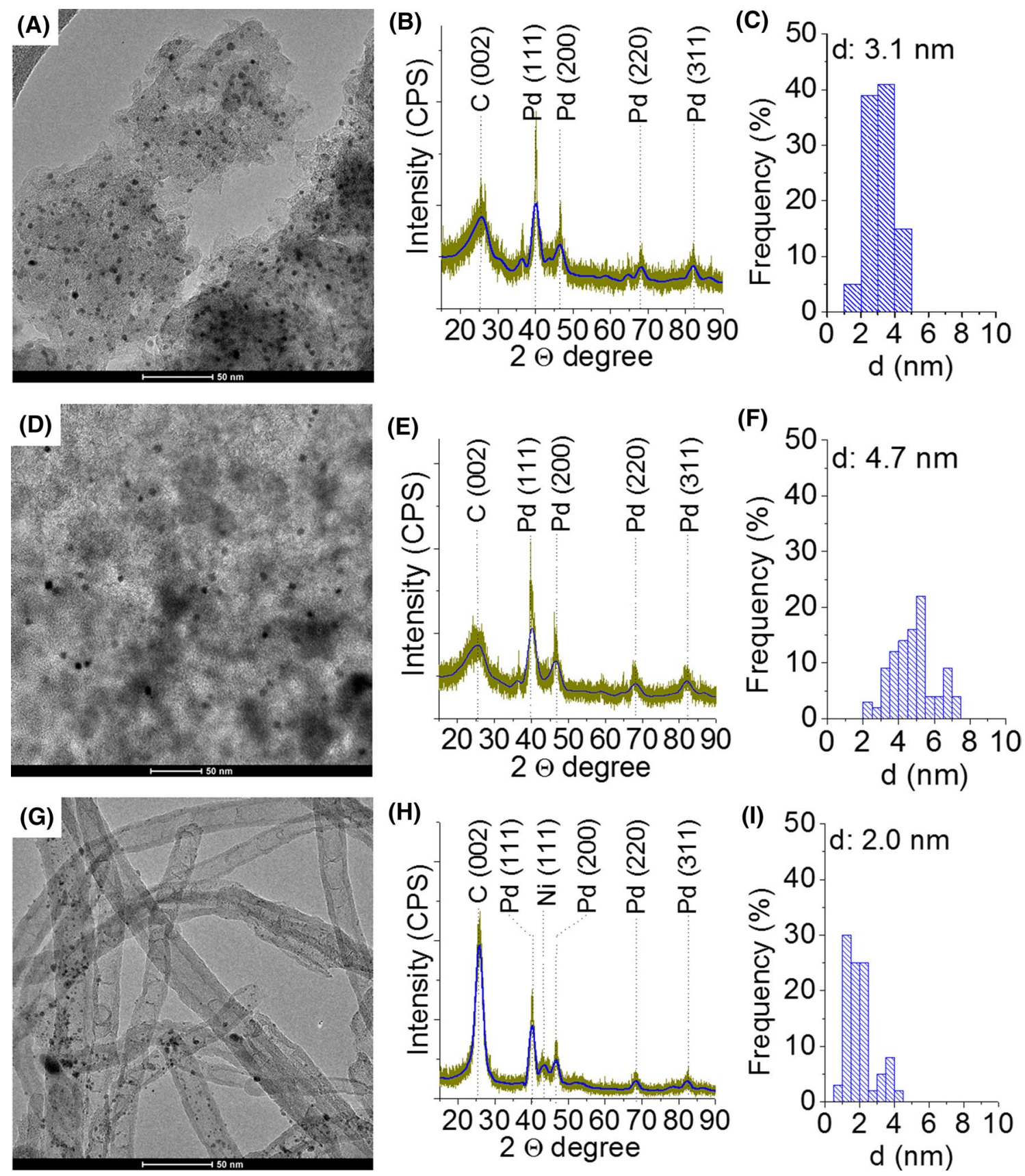

Fig. 4 The HRTEM pictures of the activated carbon (a), norit (d) and N-CNT (g) supported catalysts. XRD results of the Pd/A (c, b), $\mathrm{Pd} /$ norit (e) and Pd/N-CNT (h) catalysts. Diameter distribution of Pd

higher temperature showed much higher activity for a short time period but the deactivation of the catalyst was rapid on 973 K (Fig. 5c, d). Some characteristic data are presented in Table 1.

To establish the contribution of the Pd similar experiments were performed with the supports alone. Supports also catalyzed the dehydrogenation reaction but their effect was less than that of palladium containing catalysts (Fig. 6). particles on activated carbon (c), norit (f) and on the nanotube supports (i). $\mathrm{Pd} / \mathrm{Ac}(\mathbf{a}-\mathbf{c}) ; \mathrm{Pd} /$ norit (d-f); Pd/N-CNT (g-i)

Deposition of Pd on various carbon supports enhanced the dehydrogenation of $\mathrm{C}_{2} \mathrm{H}_{6}$.

$$
\mathrm{C}_{2} \mathrm{H}_{6(\mathrm{a})}=\mathrm{C}_{2} \mathrm{H}_{4(\mathrm{a})}+2 \mathrm{H}_{(\mathrm{a})}
$$

The high selectivity of $\mathrm{C}_{2} \mathrm{H}_{4}$ formation, $>60 \%$ at 873 $923 \mathrm{~K}$, indicates that we can count only with limited side reactions, e.g. with the decomposition of $\mathrm{C}_{2} \mathrm{H}_{4}$ or $\mathrm{C}_{\mathrm{x}} \mathrm{H}_{\mathrm{y}}$ to carbon. 

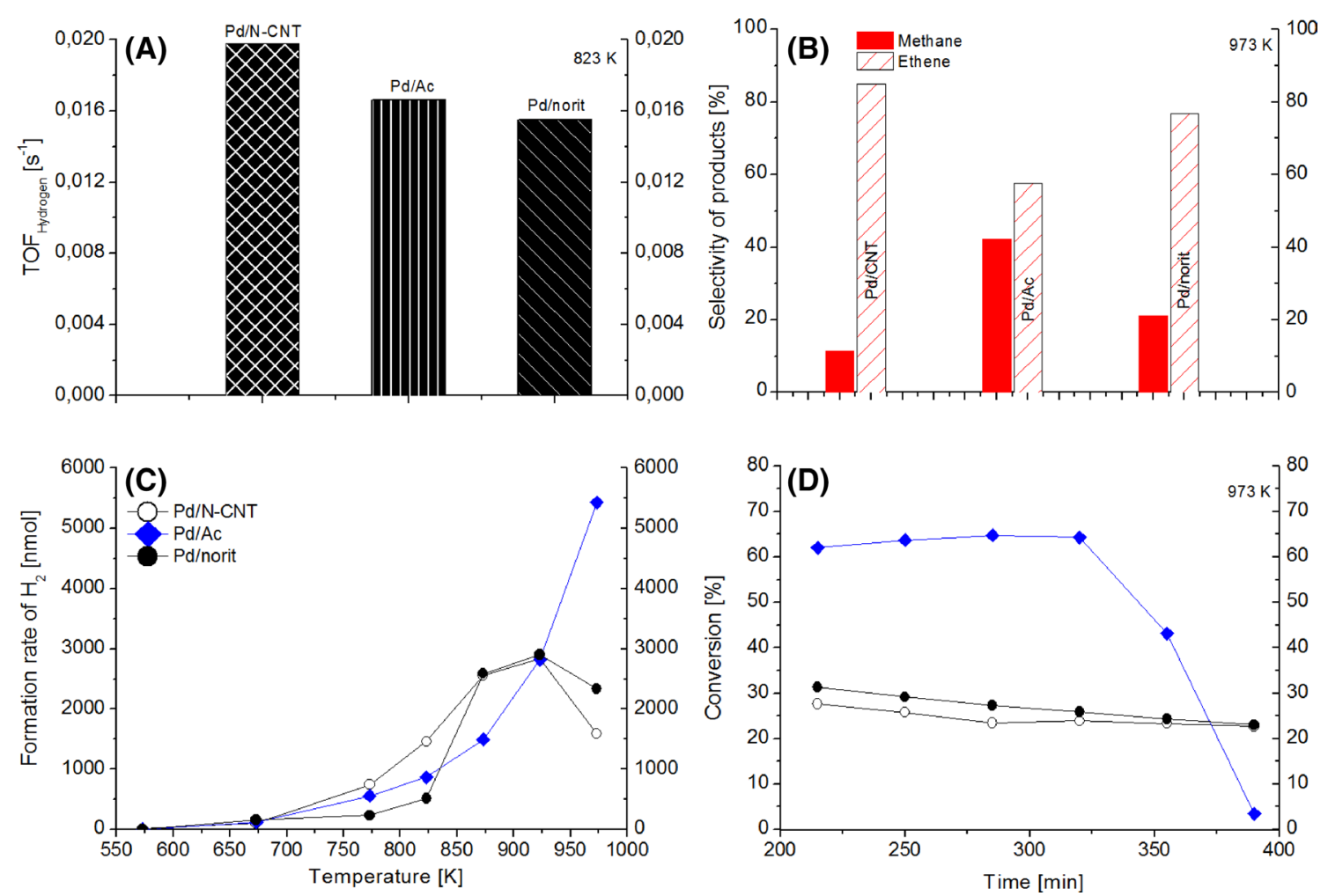

Fig. 5 Effect of different Pd deposited supports on the catalytic decomposition of ethane. TOF (a), selectivity of products at $973 \mathrm{~K}$ (b), formation rate of $\mathrm{H}_{2}$ in the function of temperature $(\mathbf{c})$, and conversion at $973 \mathrm{~K}$ time on stream $(\mathbf{d})$

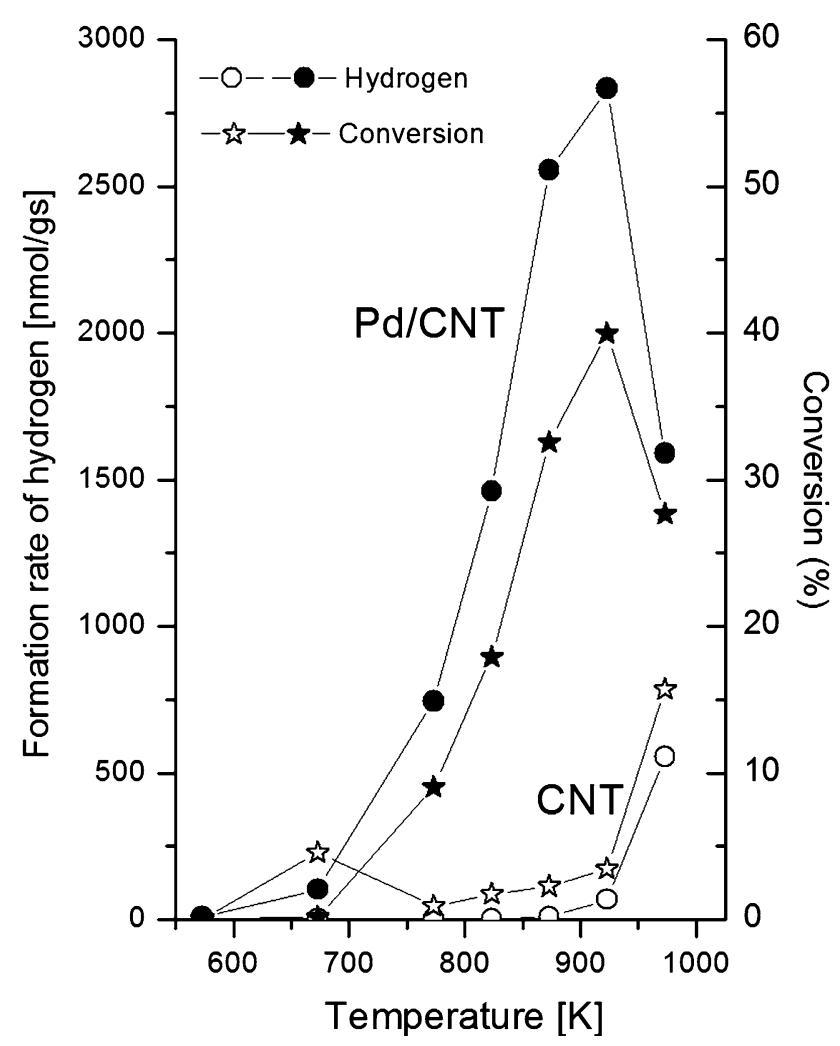

Fig. 6 Effect of palladium on the decomposition of ethane on N-CNT

$$
\mathrm{C}_{2} \mathrm{H}_{4(\mathrm{a})}=\mathrm{CH}_{4(\mathrm{~g})}+\mathrm{C}
$$

The highest selectivity to ethene $(85 \%)$ was reached on $\mathrm{Pd} / \mathrm{N}-\mathrm{CNT}$ catalyst. We noticed that with the increase of the temperature the main reaction pathway was the dehydrogenation and the formation of methane significantly decreased. Accordingly, we can count with the cracking of $\mathrm{C}_{2} \mathrm{H}_{6}$ and $\mathrm{C}_{2} \mathrm{H}_{4}$.

$$
\mathrm{C}_{2} \mathrm{H}_{6}+\mathrm{H}_{2}=2 \mathrm{CH}_{4}
$$

$\mathrm{C}_{2} \mathrm{H}_{4}=\mathrm{CH}_{4}+\mathrm{C}$

The deactivation of the $\mathrm{Pd} / \mathrm{Ac}$ at higher temperatures can be attributed to the deposition of carbon. TPR studies clearly indicated the presence of large amount of carbon deposit formed in the decomposition of $\mathrm{C}_{2} \mathrm{H}_{6}$ reaction over $\mathrm{Pd} / \mathrm{Ac}$. The carbon balance was appropriate in the reaction until $873 \mathrm{~K}$, but above this temperature the coke formation continuously increased and on $973 \mathrm{~K}$ the difference became significant. The used catalyst was examined with HRTEM (Fig. 7). On the HRTEM picture are showed the deposited carbon layers on the palladium particles, which lead to the deactivation of catalyst. However, the sintering of $\mathrm{Pd}$ particles especially on high temperatures cannot exclude. In 


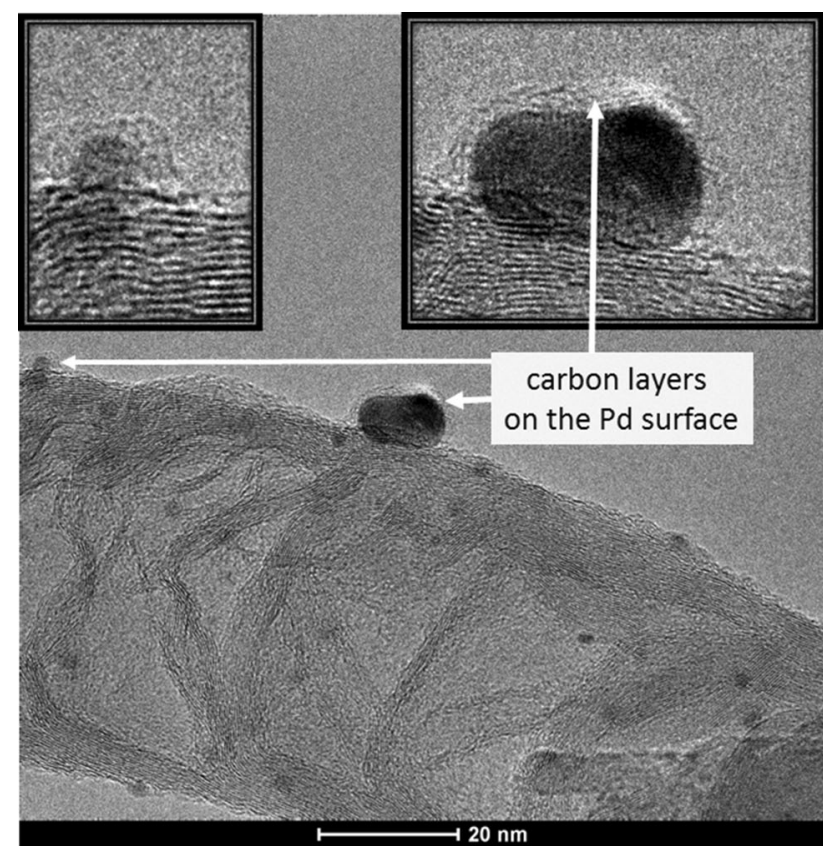

Fig. 7 HRTEM picture of the used catalyst

case of porous catalysts - for example activated carbon forms supported catalyst - not the only coking of the metal particles lead to deactivation of the catalysts. The deposited carbon block the microporous on the support surface. BET surface and pore volume measurements were confirmed the aforementioned reasons (Fig. 7). The BET surface of fresh catalyst was $328 \mathrm{~m}^{2} / \mathrm{g}$ and case of the deactivated catalyst the surface area was decreased $38.5 \mathrm{~m}^{2} / \mathrm{g}$. The BJH pore volume decreased from 0.31 to $0.10 \mathrm{~cm}^{3} / \mathrm{g}$, and the pore radius also decreased (from 18.0 to $15.5 \AA$ ).

\section{Conclusions}

In this study high nitrogen content carbon nanotube was synthesized with structural defects and these defects were most important in catalysis. The enhanced catalytic stability of nanotube supported Pd catalysts was reached in the test reactions, as opposed to the activated carbon supported catalysts. The difference in catalytic stability of these carbon supported catalysts can be explained by the absence of micro porosity in the N-CNT supported catalysts. The high energy adsorption sites on surface of N-CNT support are homogeneously dispersed, to which palladium nanoparticles attach, thus the particle size of Pd particles were decrease. In case of the activated carbon supported catalyst the palladium clusters on surface of support were larger than those on N-CNT, this can be explained by the fact that Pd first aggregates on vent of the micropores, thus blocking of the entrance of micropores, where the nucleation of palladium clusters are enhanced. The particle diameters of palladium particles were larger on activated carbon surface because the Ac has developed micropores. And it was the main reason of the fast inhibition of the active carbon on high temperature where these micropores closed up and led to the deactivation of the catalysts. On higher temperatures we had to achieve the highest ethene selectivity in the decomposition of ethane on the prepared N-CNT catalyst. The different catalytic activity for these carbon supports can also be related to an electronic alteration of the metal particle due to the electronic modification of the support by insertion of nitrogen atoms inside the carbon network. Nitrogen atoms on the surface of N-CNTs can rise the number of anchorage sites for the adsorption of the Pd. Based on the BET measurements we can conclude that the surface area and the pore volume distribution of the fresh and used catalysts is different and completely changed to the effect of the reaction circumstances. This phenomenon can be attributed to the coke deposition which decreases the micropore surface area and the micropore volume in case of used $\mathrm{Pd} /$ Ac catalyst.

- Successfully prepared and characterized the N doped CNT sample and applied as catalysts in the dehydrogenation of ethane.

- Dehydrogenation of $\mathrm{C}_{2} \mathrm{H}_{6}$ are well catalyzed by different carbon supported $\mathrm{Pd}$ catalysts and $\mathrm{Pd} / \mathrm{N}-\mathrm{CNT}$ showed the highest turnover frequency at $823 \mathrm{~K}$. The highest ethene selectivity was reached on Pd/CNT at $973 \mathrm{~K}$.

- Deposition of Pd on applied carbon supports markedly enhances the extent of the catalytic reaction mainly leading to the formation of hydrogen.

- The different catalytic activity can be explained by the absence of micropores in the case of $\mathrm{N}$ doped $\mathrm{CNT}$ catalyst.

Acknowledgments This research was partially supported in the framework of the Center of Applied Materials Science and Nano-Technology at the University of Miskolc. This work was also supported by National Research, Development and Innovation Office-NKFIH (PD 115769).

\section{References}

1. Yu Z, Fareid LE, Moljord K, Blekkan EA, Walmsley JC, Chen D (2008) Appl Catal B 84:482

2. Zhang Y, Zhang HB, Lin GD, Chen P, Yuan YZ, Tsai KR (1999) Appl Catal A 187:213

3. Bahome MC, Jewell LL, Hildebrandt D, Glasser D, Coville NJ (2005) Appl Catal A 287:60

4. Ovejero G, Sotelo JL, Rodriguez A, Diaz C, Sanz R, Garcia J (2007) Ind Eng Chem Res 46:6449

5. Chen WY, Ji J, Feng X, Duan XZ, Qian G, Li P, Zhou XG, Chen D, Yuan WK (2014) J Am Chem Soc 136:16736

6. Chambers A, Nemes T, Rodriguez NM, Baker RTK (1998) J Phys Chem B 102:2251 
7. Serp P, Corrias M, Kalck P (2003) Appl Catal A 253:337

8. Pham-Huu C, Keller N, Ehre G, Charbonniere LJ, Ziessel R, Ledoux MJ (2001) J Mol Catal A 170:155

9. Onoe T, Iwamoto S, Inoue M, (2007) Catal Comm 8:701

10. Liao HG, Xiao YJ, Zhang HK, Liu PL, You KY, Luo H, Wei C (2012) Catal Comm 19:80

11. Pereira MFR, Figueiredo JL, Oerfaó JJM, Serp P, Kalck P, Kihn Y (2004) Carbon 42:2807

12. Joseyacaman M, Mikiyoshida M, Rendon L, Santiesteban JG (1993) Appl Phys Lett 62:657

13. Endo M, Takeuchi K, Kobori K, Takahashi K, Kroto HW, Sarkar A (1995) Carbon 33:873

14. Singh C, Shaffer M SP, Windle AH (2003) Carbon 41:359

15. Collins PG (2009) Defects and disorder in carbon nanotubes. In: Narlikar AV, Fu YY (eds) Oxford handbook of nanoscience and technology: frontiers and advances. Oxford University Press, Oxford

16. Dresselhaus MA, Dresselhaus G, Saito G, Joriod A (2005) Phys Rep 409:47

17. Hussain $\mathrm{S}$, Jha $\mathrm{P}$, Chouksey A, Raman R, Islam S, Islam ST, Choudhary PK, Harsh K (2011) J Mod Phys 2:538
18. Reddy ALM, Ramaprabhu S (2007) Int J Hydrogen Energy 32:3998

19. Ono Y (1992) Catal Rev Sci Eng 34:179

20. Solymosi F (2005) Springer 25

21. Rostrup-Nielsen JR (1988) Stud Surf Sci Catal 36:73

22. Rostrup-Nielsen JR, Aasberg-Petersen K, Schoubye PS (1997) Stud Surf Sci Catal 107:473

23. Solymosi F, Németh R (1999) Catal Lett 62:197

24. Zhu H, Rosenfeld DC, Anjum DH, Sangaru SS, Saih Y, OuldChikh S (2015) J Catal 329:291

25. Solymosi F, Tolmacsov P, Süli Zakar T (2005) J Catal 233:51

26. Lear T, Marshall R, Lopez-Sanchez JA, Jackson SD, Klapötke TM, Bäumer M, Rupprechter G, Freund HJ, Lennon D (2005) J Chem Phys 123:174706

27. Reinhold-López K, Braeuer A, Romanna B, Popovska-Leipertz N, Leipert A (2015) Procedia Eng 102:190

28. Bokobza L, Bruneel JL, Couzi M (2014) Vib Spectrosc 74:57

29. Machado FM, Bergmann CP, Lima EC, Adebayo MA, Fagan SB (2014) Mat Res 17151

30. Fanning PE, Venice MA (1993) Carbon 30:721 